\title{
Remediation of degraded soils with hydrogels from domestic animal wastes
}

\author{
Isaac Mwangi ${ }^{1}$ - Grace Kiriro ${ }^{1}$ Sauda Swaleh ${ }^{1} \cdot$ Ruth Wanjau $^{1} \cdot$ Paul Mbugua $^{2} \cdot$ Jane Catherine Ngila $^{3}$
}

Received: 12 February 2018 / Accepted: 5 January 2019 / Published online: 17 January 2019

(c) The Author(s) 2019

\begin{abstract}
Introduction This study reports on water management in the fields found in arid areas by the improvement of the soil's water retention capacity. This was done using hydrogels from animal wastes to mitigate the effects of climate change that lead to rapid evaporation of water hence increased desertification rates.

Method The modification of the cow dung to hydrogels involves the oxidation of urea or uric acid from chicken dung to form compounds that can undergo a condensation reaction with cellulose in the cow dung. This formed a product with high water retention capacity.

Results The materials were characterized using Fourier transform infra-red spectroscopy and thermo-gravimetric analysis which confirmed the derivatization of some functional groups. The thermo-stability was improved, as the degradation temperatures for urea, glycerol, and chicken dung derivatives were 245,220 , and $228{ }^{\circ} \mathrm{C}$, respectively, while the unmodified form was $198^{\circ} \mathrm{C}$. The UV-Vis analysis showed no evidence of starch in the modified material which was also confirmed by Lugol's test. It was found out that modification had influence on the swelling ability giving it superabsorbent properties with swelling capacities $\left(300 \mathrm{~g} \mathrm{~g}^{-1}\right.$ ) within 5 min of moisture exposure plus a high water retention capacity of $90 \%$.

Conclusions The application of the modified materials in the growing of some selected plants showed that the moisture content could be sustained for a period of 6 weeks before the plants wilted. This confirms that the modified form of manure has potential application for hydration of plants in arid areas.
\end{abstract}

Keywords Manure $\cdot$ Wilting $\cdot$ Hydrogels $\cdot$ Plasmolysis $\cdot$ Swelling $\cdot$ Uric acid

\section{Introduction}

The need for the materials capable of absorbing and retaining large quantity of water in the soil has motivated this study with a view to overcome challenges on growth of plants in arid and semi-arid areas. In the recent past, activities such as the extensive use of fossil fuels have enhanced the greenhouse effect leading to global warming. This contributes to an unpredictable climate change

Isaac Mwangi

isaacwaweru2000@yahoo.co.uk

1 Chemistry Department, Kenyatta University, P.O.

Box 43844, Nairobi 00100, Kenya

2 Plant Sciences Department, Kenyatta University, P.O. Box 43844, Nairobi 00100, Kenya

3 Department of Chemical Technology, University of Johannesburg, Doornfontein Campus, Doornfontein, PO Box 17011, Johannesburg 2028, South Africa with a rapid evaporation of water from the soil leading to an increased desertification rate. Coupled with erratic and changing rainfall patterns, it has been very difficult to grow food crops or any other vegetation in most areas which were hitherto bread baskets within the tropics. Compost manure has been generally applied on fields in such areas to improve farming output to little or no success. Due to such experienced challenges, this study endeavoured to provide a solution on the remediation of degraded soils despite the threat of global warming. It was geared to an increased food production capacity plus vegetative cover on water stress areas to minimize desertification. This was targeted to improve the quality of soil and other plants growing media by providing the requisite quantity of water to enable them sustain growth plants and food crop growth to maturity, thus provide a suitable environment as a home of man. Biodegradable polymers have been given attention for the water absorbing/retention materials (hydrogels) due to their safety, biocompatibility, hydrophilicity, and 
biodegradability (Nagahara and Matsuda 1996). Starch is in most abundant naturally occurring polymer hence very attractive to form physical gels under specific conditions by cross linking with fairly inexpensive reagents (Mainka et al. 2015). Regarding moisture content of the soil, manure has been known and studied by different authors. However, it has been found that it is not in itself capable to sustain growth of crops to maturity (Shibayama 2012). This behavior is due to an equilibrium established between manure and the moisture in the soil, whose ionic strength strongly affects the water holding capacity (Shibayama 2012). The presence of starch, moisture, and ambient temperature is a suitable environment for bacterial action and growth of microorganisms which reduces the quantity of manure applied in the farms; thus, affecting the time, it provides moisture in the farms. However, the presence of urea and ammonium compounds in the modified manure increases antibacterial activity and inhibits the growth of microorganisms, thus providing extended time for the provision of the very much needed water to the plants (Kaye 1968). This value addition of manure by modification is due to the formation of a carbamate after the treatment the starch in the manure with amines, urea, or uric acid. Carbamates have a high antibacterial activity, hence lengthens the life of the modified product (Kaye 1968).

Manure is derived from herbivorous animals and is predominantly the metabolic remnants of living tissue and parts of the food that was not digested like cellulose and lignin, and thus, the cow's dung components are fiber or cellulose in nature. This material has a considerable drawback in that it lacks pockets (spaces) to hold the water. This study exploited this abundant and pulverized form of starch material from the cow-dung manure to improve the quality of the product by synthesizing a novel manure gel through modification. In this study, different derivatives were successfully obtained by modification (cross linking) with urea, glycerol, and uric acid from chicken dung to form different manure gels separately (Zhou et al. 2011). Chicken dung is readily available and has a high content of uric acid.

The modification process was attained through activation of the cellulose and then treated with urea, glycerol or the uric acid material from chicken dung separately. Before the cross linking, the cow-dung manure was activated by first treating it with a solution of iron (II) in hydrogen peroxide at room temperature, where the $\mathrm{Fe}^{2+} / \mathrm{H}_{2} \mathrm{O}_{2}$ provided free radicals and then treated with the cross-linking agent.

In the reaction using the chicken dung, the bio-material was first treated with dilute nitric acid the resultant diluted with dilute ammonia, and then, the resulting uric material used as the cross-linking agent. The reaction Scheme 1 shows the possible equation of reaction that took place during modification.

The uric acid is oxidized by the action of nitric acid (V) to form alloxan and urea. Two molecules of alloxan undergo a condensation reaction with ammonia to form murexidic acid (Wang et al. 2010; Zhang et al. 2009). The murexidic acid is polyfunctional and its reaction with cellulose is due to the attachment of the polyfunctional murexidic group via esterification with a cellulosic hydroxyl group (Wang et al. 2010). Further multi-reactions through esterification with another cellulosic hydroxyl group occur, producing a cross-link between cellulose chains (Wang et al. 2010). The reaction mechanism is based on an intermediate attachment of the murexidic amine oxide moiety to celluloses hydroxyl group through an esterification reaction (Metters 2006). This is achieved through the exposure of new cellulose units in the cow-dung manure which have a proper chemical connectivity of forming a new intra-molecular murexidic amine oxide moiety with the adjacent murexidic acid unit (Metters 2006). Further reaction with a cellulose hydroxyl of another chain can then lead to cross linking. This enabled the material to acquire some swelling ability and increased its water holding capacity. The block diagram (Scheme 2) represents the design of the manure modification process.
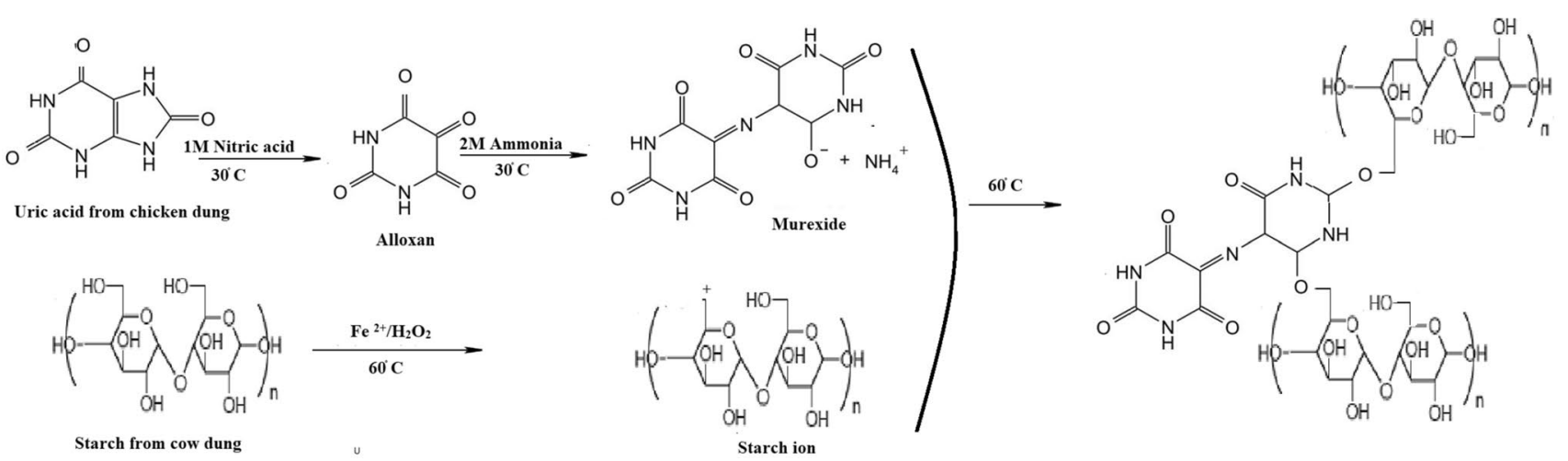

Scheme 1 Reaction scheme for modification of cow-dung manure with uric acid from chicken dung 


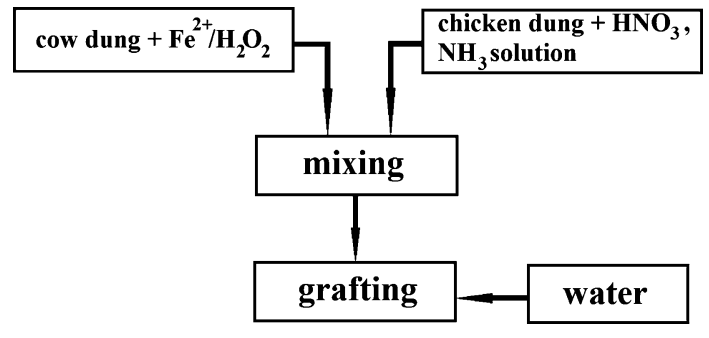

Scheme 2 Block diagram for the modification process

The scheme shows a simple modification process that can be done by persons with limited skills and facilities safely and proficiently after a short training program.

\section{Materials and methods}

\section{Materials}

Cow and chicken dung materials were obtained from smallscale farmers residing in Kiamumbi (Kiambu-County of Kenya). Urea and glycerol were purchased from E. Merck (Germany). All the reagents were of analytical grade and used without further purification. Distilled water was used for the synthesis of the manure gels.

Characterization of functional groups within the analyte materials was done using a Shimadzu IR Prestige- 21 spectrometer model 800 series from 4000 to $400 \mathrm{~cm}^{-1}$ with scan speed $20 \mathrm{~cm}^{-1}$. The thermal stability of the resulting modified manure was done using differential scanning calorimeter (DSC), Shimadzu, DSC 60-Bioer Technology (China). This was to investigate the effect of heat on the change in mass of the material. The extent of modification was investigated using UV-Vis spectrophotometer, Technology Quality Innovation analytikjena specord-200 plus (Germany).

\section{Procedure}

\section{Sample preparation}

In the laboratory, the cow and chicken dung material were dried in an oven at $60^{\circ} \mathrm{C}$ for $12 \mathrm{~h}$, cooled in desiccators and later pulverized in a mortar to a powder and stored in clean plastic bags.

\section{Preparation of manure gels}

The cross linking of manure glycerol was done as was proposed by Wawro and Kazimierczak (2008) who studied the mechanical strength of potato starch cross linked with glycerol. In that study, they observed that the resulting material decreased its mechanical strength and increased in volume (elongated) upon exposure to moisture. In this study, a sample $20.0 \mathrm{~g}$ of manure were accurately weighed was introduced into a mixing tank and $100 \mathrm{ml}$ of water with vigorous agitation. This was followed by the addition of $50 \mathrm{ml}$ glycerol, and the resultant heated on a water bath at $60{ }^{\circ} \mathrm{C}$ for $2 \mathrm{~h}$. A pasty slurry material formed and was cooled to room temperature. It was transferred into a plastic bag, sealed, and then left to stand for $(168 \mathrm{~h}) 7$ days. The resulting hydrogel obtained was vacuum dried at $60.0^{\circ} \mathrm{C}$ until a constant weight was obtained. This material was then milled to averages 60-80 mesh (Peppas et al. 2006).

The method of cross linking of manure with urea adopted in this study was as proposed by Chowdary and Chandra (2009) when treated starch with urea to form starch-urea carbamate. The starch-urea carbamate formed was a hydrophilic water swellable polymer. In this study, the urea manure gel was done by weighing accurately $20.0 \mathrm{~g}$ of dried manure into the mixing tank and $100 \mathrm{ml}$ of $25 \%$ urea solution. The mixture was heated to boiling with continuous stirring for $30 \mathrm{~min}$. The resulting manure-urea polymer formed was dried then transferred into a plastic bag, sealed, and then left to stand for (168 h) 7 days. The resulting hydrogel obtained was vacuum dried at $60.0^{\circ} \mathrm{C}$ until a constant weight was obtained. This material was then milled to averages 60-80 mesh (Peppas et al. 2006).

The chicken-manure gel was prepared by taking a dry sample $(20.0 \mathrm{~g})$ of previously dried cow dung into a mixing tank, $100 \mathrm{ml}$ with distilled water added plus $15.0 \mathrm{ml}$ of $35 \%$ hydrogen peroxide, and $5.0 \mathrm{~g}$ of iron (II) sulfate, thoroughly mixed and the product heated at $60.0{ }^{\circ} \mathrm{C}$ for $2 \mathrm{~h}$. To the resulting mixture, $20.0 \mathrm{~g}$ of dried chicken dung were added followed by $10.0 \mathrm{ml}$ of $1.0 \mathrm{M}$ nitric acid and $15.0 \mathrm{ml}$ of $1.0 \mathrm{M}$ ammonia solution. The mixture was then heated at $60^{\circ} \mathrm{C}$ for $2 \mathrm{~h}$. A pasty slurry material formed was cooled to room temperature dried and then transferred into a plastic bag, sealed, and then left to stand for (168 h) 7 days. The resulting hydrogel obtained was vacuum dried at $60.0^{\circ} \mathrm{C}$ until a constant weight was obtained. This material was then milled to averages 60-80 mesh (Peppas et al. 2006).

\section{Determination of the gel fraction}

The gel fraction was determined as proposed by Kampouris and Andreopoulos (1989). In our study, the manure gel was taken in the standard tea bags and immersed in distilled water for $12 \mathrm{~h}$ to remove the soluble fraction. The gel was then dried to a constant weight under vacuum at $50.0{ }^{\circ} \mathrm{C}$. The soluble fraction in the samples was obtained using the following equation:

Soluble fraction $=\frac{W_{\mathrm{o}}-W_{\mathrm{g}}}{W_{\mathrm{g}}} \times 100 \%$, 
where $W_{\mathrm{g}}$ is the weight of dry hydrogels after extraction and $W_{\mathrm{o}}$ is the initial weight of the hydrogel.

\section{Swelling rate studies}

The swelling rate of manure gel was determined by gravimetric method. The dried gel sample $\left(W_{\mathrm{o}}\right)$ was immersed in $30.0 \mathrm{ml}$ distilled water and dispersed with magnetic stirring at $150 \mathrm{rpm}$ at room temperature. The swollen sample was filtered at desired time; thus, excess water was removed by hanging the sieve until no more water dropped off. Then, the wet hydrogels were weighed $\left(W_{\mathrm{t}}\right)$ (Zhang et al. 2007a, b). The swelling ratio was calculated using the following equation:

Swelling ratio $=\frac{W_{\mathrm{o}}-W_{\mathrm{t}}}{W_{\mathrm{o}}}$,

where $W_{\mathrm{t}}$ is the weight of the swollen gel at time $t$, and $W_{\mathrm{o}}$ is the initial weight of the dried gels.

The equilibrium swelling ratio or water content, given in Eq. 3 is generally used to describe the swelling behavior of hydrogels:

Equilibrium swelling ratio $=\frac{W_{\text {swollen }}}{W_{\text {dry }}}$,

where $W_{\text {swollen }}$ is the weight of the swollen gel and $W_{\text {dry }}$ is the weight of the dry gel.

\section{Characterization}

\section{FTIR characterization}

The cow dung-urea, cow dung-glycerol, cow dung-chicken dung hydrogel, and cow dung were analyzed using the ATR mode on Shimadzu IR Prestige-21 spectrometer model 800 series from 4000 to $400 \mathrm{~cm}^{-1}$ with scan speed $20 \mathrm{~cm}^{-1}$ and all spectra were displayed in multipoint base line correction (Zhang et al. 2007a, b).

\section{Thermal analysis}

Approximately $5.0 \mathrm{mg}$ of the resultant manure gel samples were used for each analysis. The scanning temperature was ranging from 10 to $2008.0^{\circ} \mathrm{C}$ at a heating rate of $58.0^{\circ} \mathrm{C} \mathrm{min}^{-1}$. The adopted thermal cycle was: (1) heating $10-1008.0{ }^{\circ} \mathrm{C}$; (2) isotherm at $1008.0{ }^{\circ} \mathrm{C}$ for $3 \mathrm{~min}$; (3) cooling from 1008.0 to $10.0^{\circ} \mathrm{C}$; (4) heating from 1008.0 to $2008.0^{\circ} \mathrm{C}$; (5) isotherm at $2008.0^{\circ} \mathrm{C}$; and (6) cooling until room temperature. In this experiment, an empty pan was used as a reference (Zhang et al. 2007a, b).

\section{Karl Fischer moisture analysis}

For moisture determination, a METTLER TOLEDO DO307 KF moisture analyzer was used. Solid KF (contains iodine, sulfur dioxide, and imidazole) reagent was used as oven standards, with water contents of $5.5 \%$ and $1 \%$, respectively. $\mathrm{KF}$ determination of water is based on the standard reaction (Eq. 4) for the KF reaction:

$\mathrm{ROH}+\mathrm{SO}_{2}+3 \mathrm{RN}+\mathrm{I}_{2}+\mathrm{H}_{2} \mathrm{O} \rightarrow(\mathrm{RNH}) \mathrm{SO}_{4} \mathrm{R}+2(\mathrm{RNH}) I$.

The sample contained the same average amount of water, and was taken quickly to minimize the absorption or release of moisture. It was stored in a tightly sealed bottle glass bottle, and thus, air moisture did not penetrate. Solid sample was pulverized in a mortar to gain access to the trapped water and the moisture extracted using methanol/ homogenizer. The rest of the procedure adopted METTLER TOLEDO V2 sample preparation protocol.

\section{Determination of the total uncross-linked starch in the manure gels}

This was done using both classical and instrumental method, thus by UV-visible spectroscopy and titration methods.

The unmodified and modified materials were pulverized into a powder. $2.0 \mathrm{~g}$ of each sample was put into a test tube and $4.0 \mathrm{ml}$ of distilled water added and stirred thoroughly. The mixture was allowed to stand for a $10 \mathrm{~min}$. A $2.0 \mathrm{ml}$ sample of the clear liquid was then transferred into another test tube and to it $2.0 \mathrm{ml}$ of iodine solution added and the colour change observed.

\section{lodometric titration}

A comparison of the extent of cross linking was also done by titrimetric method, where the non cross-linked starch was expected to form a starch iodine complex as done by Mwangi et al. (2013). The excess iodine solution was determined by titration method using the standard sodium thiosulphate solution. The total uncross-linked starch content was determined by back titration of excess iodine using the standard sodium thiosulphate solution as reported by Zimmermann and Andersson (2012), as shown in the following equation:

$I_{3(\mathrm{aq})}^{-}+\left(\mathrm{C}_{6} \mathrm{H}_{12} \mathrm{O}_{6}\right)_{n} \rightarrow\left(\mathrm{C}_{6} \mathrm{H}_{12} \mathrm{O}_{6}\right)_{n} \mathrm{I}_{3}^{-}$.

\section{UV-visible spectrophotometry}

The cow-dung manure gel was vibrated using a wise clean sonicator model PS-08A 1.3L (Guangdong, China). The analysis to confirm the extent of cross linking was done 
on both the cross-linked and uncross-linked material. This was carried out on a Technology Quality Innovation analytikjena specord-200 plus (Germany) UV-Vis spectrophotometer, with the instrument set on a normal wavelength range of between 190 and $1100 \mathrm{~nm}$.

\section{Application of the hydrogel and moisture measurements and variation schedule}

The experiment was carried out by mixing constant mass $(2.0 \mathrm{~kg})$ of previously prepared polystyrene substrate material (soilless media) anchored with suitable nutrients with varying masses of the different derivatives of the manure hydrogels in different 21 containers. The containers used in the study had four holes at the bottom that could allow water to flow out freely to provide sufficient drainage. The resulting mixtures in the containers were transferred to green house; $500 \mathrm{ml}$ of water added and then allowed to equilibrate for $3 \mathrm{~min}$. Then, the different plants (spinach and potato) were planted in each of the containers. After every $24 \mathrm{~h}$, a sample $(2.0 \mathrm{~g})$ of the mixture was taken from the surface and the moisture content determined. A control experiment was done without a plant and the results compared.

Thereof, every day, the Karl Fischer moisture meter was used to measure the levels of moisture in each sample three times, and average is taken to ensure more accurate results. This was done every day for 8 weeks. Each day observations of the appearance of the plants were made.

\section{Leaf growth profile}

From each of the containers, where the study plants were growing, a selected leaf was identified from each of the different experimental plants and their growth rates monitored upon watering at different time intervals. This was to give information regarding the growth processes as a function of time and the different derivatives used as a source of water. The growth dynamics were done as proposed by Voorend et al. (2014). It was done by measuring the respective length of the leaves of the different plants at regular time intervals to derive the leaf elongation rate (LER) profile over time. From the LER profile, parameters such as maximal LER and leaf elongation duration (LED), essential information was obtained giving details relating the growth changes as a function of changing soil moisture content. The measured data were fitted in a Microsoft Excel-based tool called LEAF-E that allows a non-linear regression modeling of leaf length measurements for extraction of leaf growth parameters.

\section{Results and discussion}

The synthesized products (urea, glycerol, and chicken dung cross linked) formed were dark grey in colour. The products were analyzed using differential analytical techniques before application for the growth of some selected food crops.

\section{Characterization}

\section{FTIR analysis}

The unmodified cow-dung manure samples were characterized using FTIR and the resulting spectrum is presented in Fig. 1.

The results show a wide bands observed at $3421.81 \mathrm{~cm}^{-1}$ in the spectra of cow-dung manure. That can be attributed to the $\mathrm{O}-\mathrm{H}$ stretching of the amylopectin and its width were ascribed to the formation of inter- and intra-molecular hydrogen bonds (Zhang et al. 2007a, b). The bands at $2919.0 \mathrm{~cm}^{-1}$ were due to the asymmetric stretching of $\mathrm{C}-\mathrm{H}$, while the bands at $1653.0 \mathrm{~cm}^{-1}$ ascribed to $\mathrm{C}=\mathrm{O}$ in acids as well as the absorbed water and the bands $1456.0 \mathrm{~cm}^{-1}$ are assigned to lignin and at $1417.0 \mathrm{~cm}^{-1}$ to the angular deformation of $\mathrm{C}-\mathrm{H}$ (Peppas et al. 2006). The $\mathrm{C}-\mathrm{O}-\mathrm{C}$ ether bond shows stretching at $1077.0 \mathrm{~cm}^{-1}$, while the $\mathrm{Si}-\mathrm{O}$ silane bond shows stretching at $597.0 \mathrm{~cm}^{-1}$ (Zhang et al. 2007a, b).

The cow dung was then treated with chicken dung, urea, and glycerol as the cross-linking agents in a free-radical polymerization reaction using iron (II) ions in hydrogen peroxide redox system. The mixture was left to equilibrate for 7 days. The resulting products were then analyzed using ATR-FTIR spectroscopy. The resulting spectra are shown in Fig. 2.

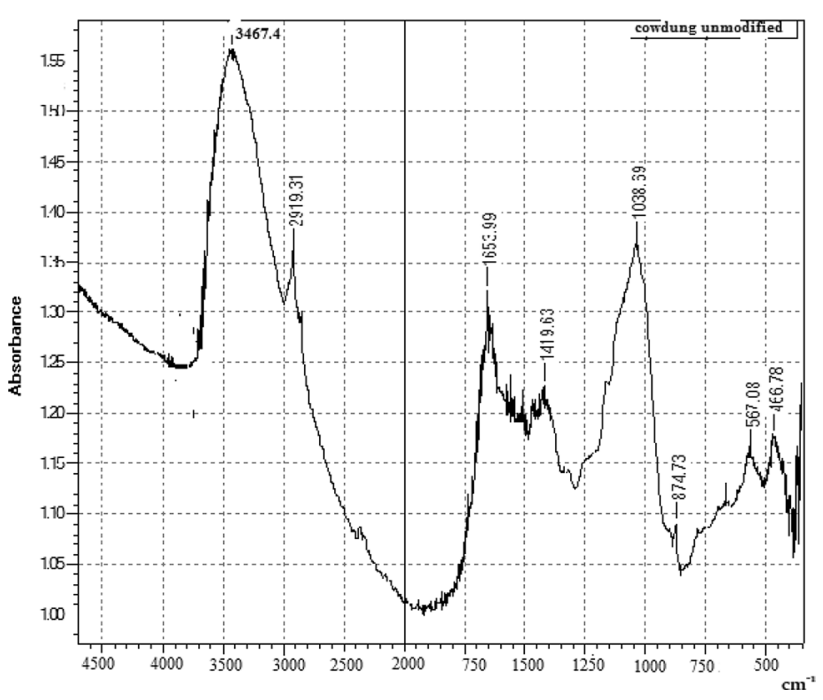

Fig. 1 FTIR spectra of unmodified cow dung 

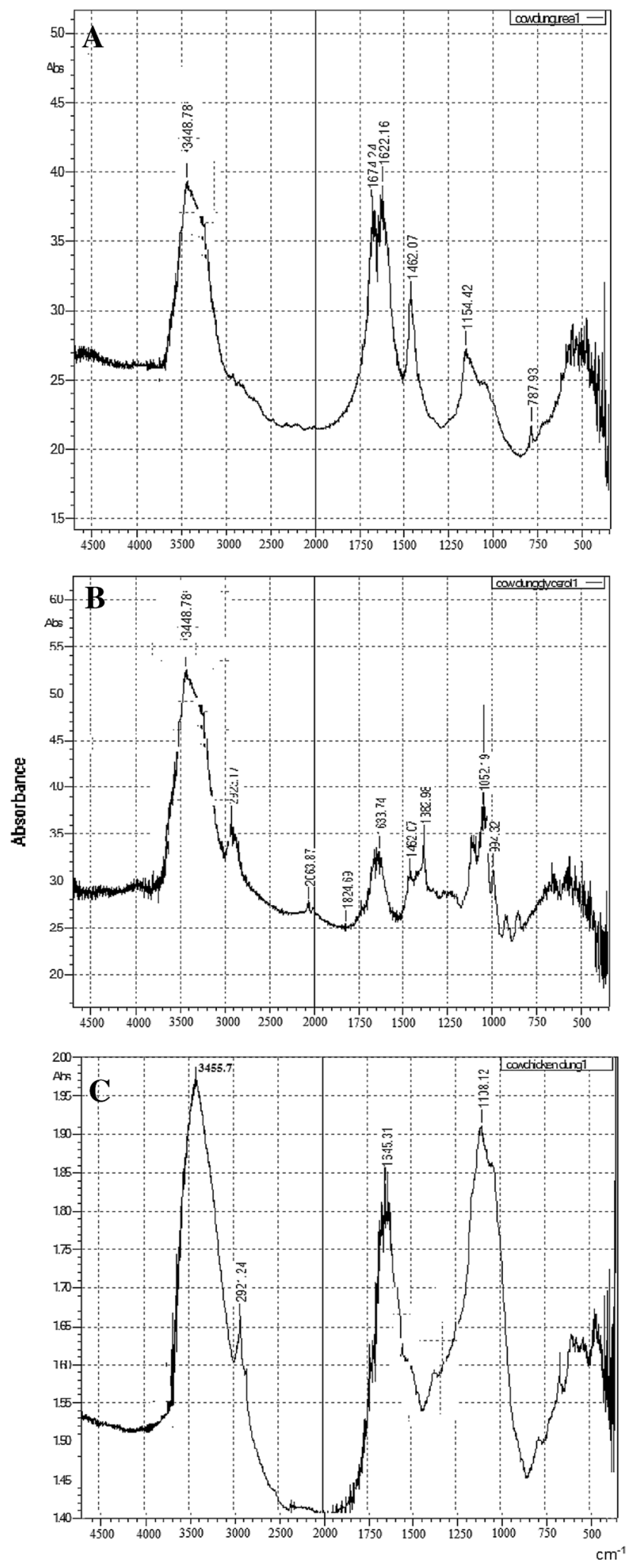

Fig. 2 FTIR for cow dung - a urea, b glycerol, and $\mathbf{c}$ chicken dungmodified gels
All the manure gels for the three different cross-linking agents had a signal observed at $3418.38 \mathrm{~cm}^{-1}$, but at different intensities, this could either be due to $\mathrm{OH}$ groups from cellulose or NH stretching of urea units or both (Zhang et al. 2007a, b). A weak band at $2933.3 \mathrm{~cm}^{-1}$ was found in the glycerol and chicken dung-modified materials only and could be assigned to $\mathrm{C}-\mathrm{H}$ stretch (Zhang et al. 2007a, b). This is a confirmation modification, as urea does not have $\mathrm{C}-\mathrm{H}$ bonds The absorption at $1643.17 \mathrm{~cm}^{-1}$ is attributed to the system $(\mathrm{C}-\mathrm{O}-\mathrm{C})$, skeletal mode vibration of $\alpha-1,4-$ glycosidic linkage, the band at $1650.0 \mathrm{~cm}^{-1}$ is due to water in the amorphous region, and the $\mathrm{C}-\mathrm{O}-\mathrm{C}$ ether bond shows stretching at $1042.4 \mathrm{~cm}^{-1}$ (Peppas et al. 2006; Zhang et al. $2007 \mathrm{a}, \mathrm{b})$. The band at $1427.0 \mathrm{~cm}^{-1}$ in all spectra indicated that all samples contained a mixture of crystallized cellulose and amorphous cellulose. The bands at 1369.0, 1315.0, and $1157.0 \mathrm{~cm}^{-1}$ are assigned to $\mathrm{CH}$ stretching, $\mathrm{CH}_{2}$ wagging, and C-O stretching in cellulose (Zhang et al. 2007a, b). These results shows that the cow-dung molecules were cross-linked effectively by all the three cross-linking agents and that the chicken dung gels compared well with the commercial cross linkers.

\section{Thermal analysis}

The results of TGA data of both the modified and unmodified cow-dung manure are presented in Fig. 3. The results show the percent mass as a function of sample temperature under a nitrogen purge.

The results show the variation of mass with changing temperature of the raw cow-dung form and its derivatives. They were consistent in inherent properties and started to degrade above $170.0{ }^{\circ} \mathrm{C}$ by two-step decomposition reactions.

The figure shows a constant mass of the samples up to a temperature of $100{ }^{\circ} \mathrm{C}$. This could be attributed to loss of waster. It is evident that cow dung (manure) had the highest rate of loss of water unlike the modified form. This is demonstration that modification has a positive effect on the retention of water. After $100{ }^{\circ} \mathrm{C}$, the rate of loss of mass was different. It was higher, where the manure was modified with chicken dung (bio-material) unlike when modified with urea or glycerol which is commercially acquired chemicals. The onset starting points for the first degradation steps for cow dung-urea, cow/chicken dung, cow dung-glycerol, and cow-dung-unmodified were at 245.0, 220.0, 228.0, and $198.0^{\circ} \mathrm{C}$, respectively. The variation is due to the strength of the bond, which can be attributed to the atoms involved in the cross linking, where the $\mathrm{O}-\mathrm{N}-\mathrm{C}$ group in urea-manure gel has high electron density compared to $\mathrm{C}-\mathrm{O}-\mathrm{C}$ group in glycerol-manure, hence strong bonds in urea-manure gel (Kaneko et al. 1995). 
Fig. 3 TGA curves for cow dung, cow dung-chicken dung gel, cow dung-urea gel, and cow dung-glycerol gel

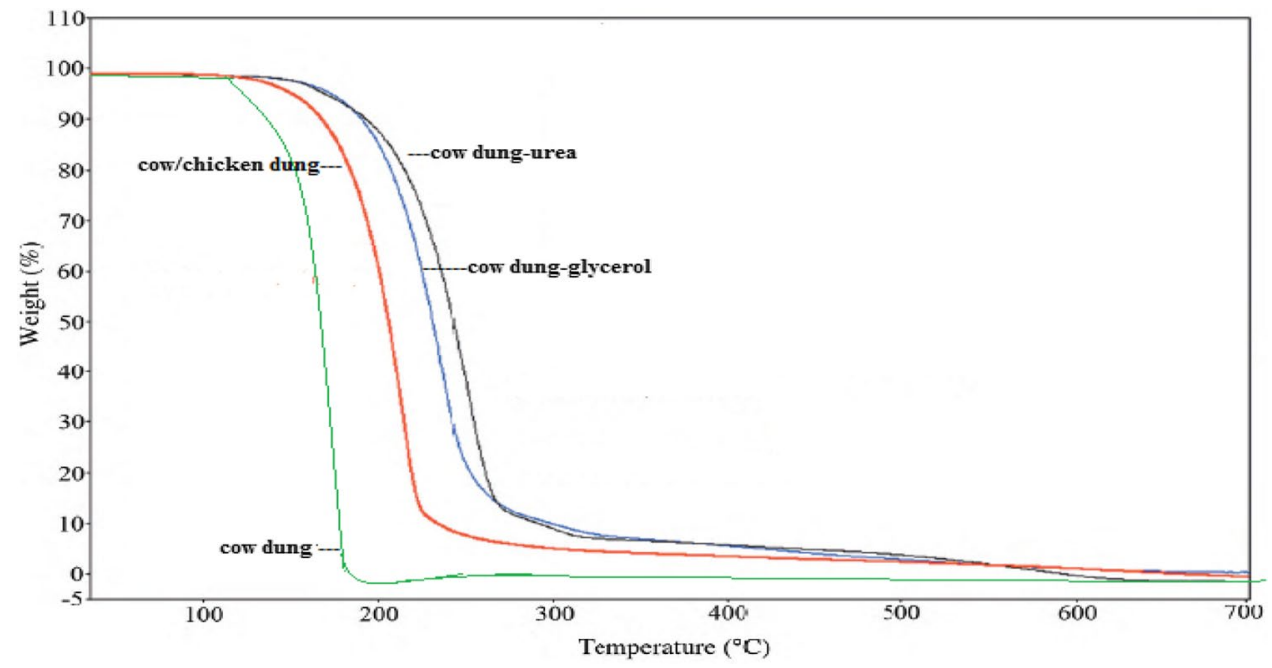

Structural relationships between the amorphous regions and crystallites within the cow dung are responsible for the sharpness of the transition and the temperature at which each occurs. The variation of the peak heights and sharpness is as a result of different degrees of crystallinity of gel in different forms (Kaneko et al. 1995; Yoshida et al. 1996).

From these results, it can be concluded that cross linking of the manure improves the thermal stability of the manure and thus suitable application in hot arid areas. This can be attributed to the cross linking, which disturbed the intra and inter molecular hydrogen bonds of the cellulose.

\section{Determination of starch iodine complex}

The starch iodine complex was determine by both classical and instrumental method thus by UV-visible spectroscopy and titration methods.

\section{Determination of starch iodine complex by UV- visible spectrophotometry}

UV-visible spectroscopic method was used to determine the extent of cross linking through the quantification of the starch iodine complex which has wavelength of maximum absorption of between 250 and $340 \mathrm{~nm}$ (Karve and Kale 1992).

\section{Calibration}

A curve was prepared using varying concentrations of the starch (0.01-0.1 $\mathrm{g} \mathrm{l}^{-1}$ starch). Their respective $\mathrm{pH}$ values were adjusted to 7.0 and then treated with iodine solution $\left(0.05 \mathrm{~mol} \mathrm{l}^{-1}\right)$ and then allowed to equilibrate for $45 \mathrm{~min}$. Their absorption measurements were recorded using UV-Vis spectrophotometer from which a calibration curve was made. The results are presented in Fig. 4

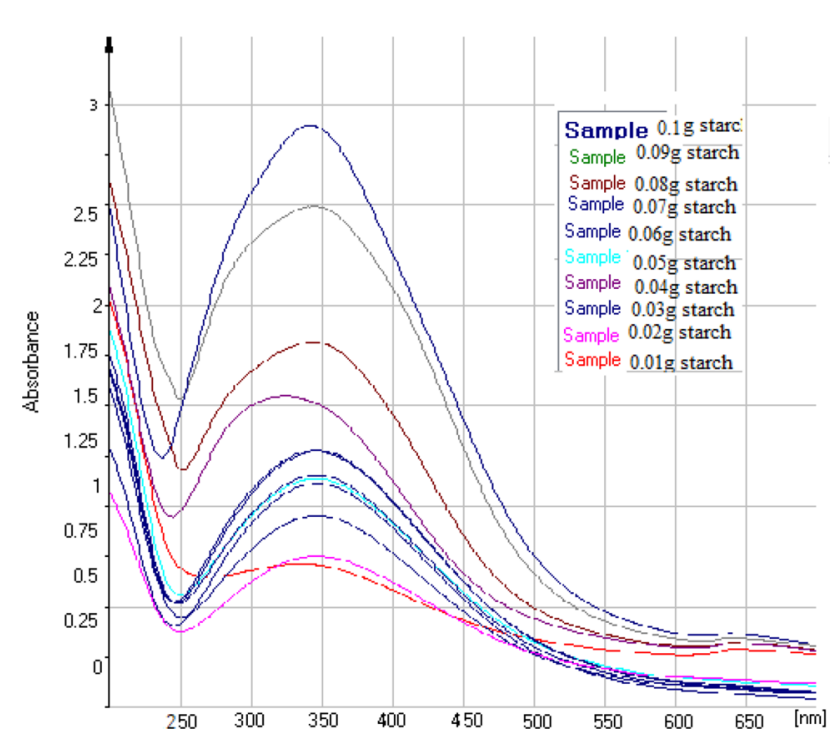

Fig. 4 Absorbtion spectra of varying concentrations of starch in iodine

The spectra presented in Fig. 4 show maximum absorbtion values versus concentration of the analyte solutions. It was observed that the absorbance readings increased with an increase in the concentration of starch in solution. From that information, a linear calibration curve was obtained (not presented in the text) by making a plot of varying starch masses against absorbance.

Starch is a polar compound, and when dissolved in water, starch dissociates to form simple units of varying monomers (González-Pérez et al. 2008). These dissociated repeating units of starch in water react with the iodine to form colloids (González-Pérez et al. 2008). Results obtained show the existence of a linear relationship between absorbance and concentration of the starch. The curve had a correlation coefficient $\left(R^{2}\right)$ of 0.998 with a molar adsorptive of 
$2450 \mathrm{~mol}^{-1} \mathrm{~cm}^{-1}$ and was adopted for calculation of starch in the samples as it obeys the Beer-Lambert law (Mwangi et al. 2013). In another experiment, the spectrum of the unmodified material (chicken and cow dung) was treated with iodine solution and their respective absorption measurements recorded using UV-Vis spectrophotometer. The results obtained are presented in Fig. 5.

From the figure, there is the evidence of starch as confirmed by a signal between 250 and $350 \mathrm{~nm}$. The absorbance readings obtained from the samples were fitted in the linear calibration curve (Fig. 5). This gave a concentration of the starch as 300.0 and $213.0 \mathrm{mg}$ cow dung and in chicken dung, respectively. A similar analysis was done, where samples of the parent and its modified forms (chicken dung, urea, and glycerol) were treated with Lugols reagent. The results obtained are presented in Fig. 6.

Some absorbtion bands at the region between 590 and $650 \mathrm{~nm}$ were observed. They assigned be due to chlorophyll moieties in the dung material (Wang et al. 2007). There is the presence of chromospheres responsible for absorption at the region between 200 and $340 \mathrm{~nm}$ in the unmodified parent material and not in the modified forms. The presence of that band in the unmodified manure is due to starch iodine complex (Mwangi et al. 2013). The results reveal absence of starch in the modified manure is evidence that cross linking indeed took place. This confirms the earlier findings done using Lugols reagent, where the modified material did not produce a positive iodine test.

\section{Determination of starch iodine complex-iodometric titration}

The results obtained from the iodometric titration data showing the relationship between the excess iodine and the uncross-linked starch were recorded and presented graphically, as shown in Fig. 7.

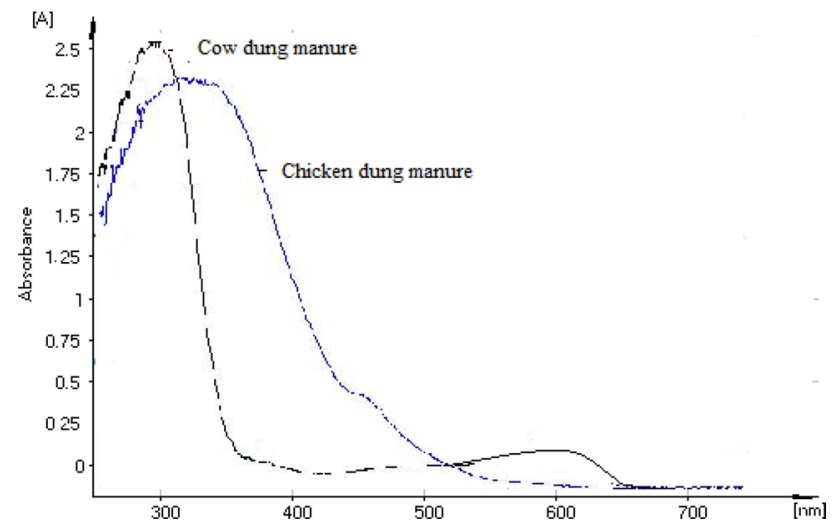

Fig. 5 Absorbtion spectra of the unmodified manure-iodine complex

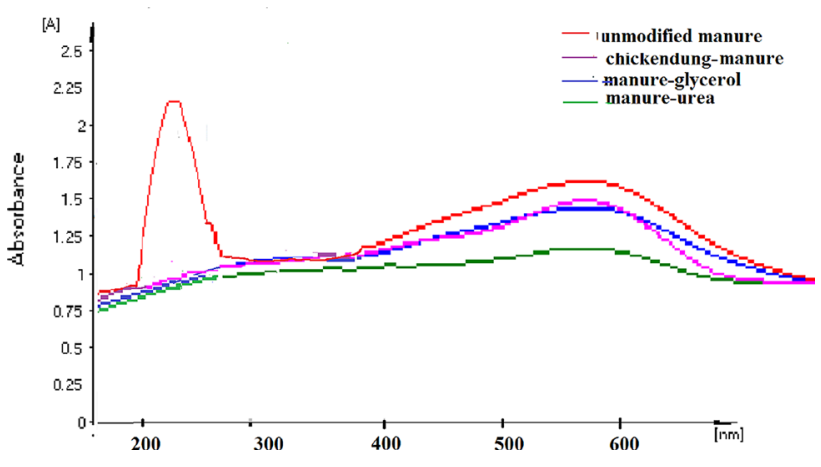

Fig. 6 Absorbtion spectra of the modified manure-iodine complex

Cow dung-urea $\left(1.2 \mathrm{mg} \mathrm{g}^{-1}\right)$ and cow dung-glycerol $\left(1.5 \mathrm{mg} \mathrm{g}^{-1}\right)$ gave a relatively low content of starch which suggested that they formed manure gels, where cellulosic fibers were well cross-liked. The cow/chicken dung gels also showed low content of starch $\left(4.0 \mathrm{mg} \mathrm{g}^{-1}\right)$ compared to unmodified manure with $\left(64.0 \mathrm{mg} \mathrm{g}^{-1}\right)$. The unmodified manure is a material that encourages growth of microorganisms that then contribute to bacteria action hence loss of matter. To inhibit both the fungal and bacterial activity, the modification process which yields carbamates which are sufficient to deter the growth of microorganisms and lower life forms thus improving the quality and life of the material. (Kaye 1968).

\section{Swelling ratios}

The results obtained from the experimental data showing the relationship between the gels swelling rates against time were recorded and presented graphically, as shown in Fig. 8.

The physical behavior of hydrogels is dependent on their equilibrium and their dynamic swelling behavior in water. In this study, the Flory-Huggins theory was used to calculate the thermodynamic behavior of hydrogel swelling ratios (Metters 2006; Suzuki et al. 2008).

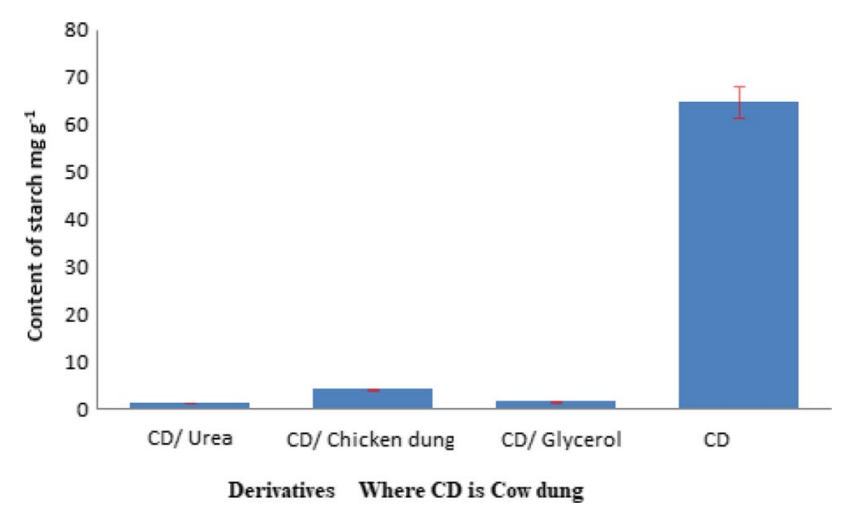

Fig. 7 Iodometric Titrations for the uncross-linked starch 
Fig. 8 Swelling rate as a function of time

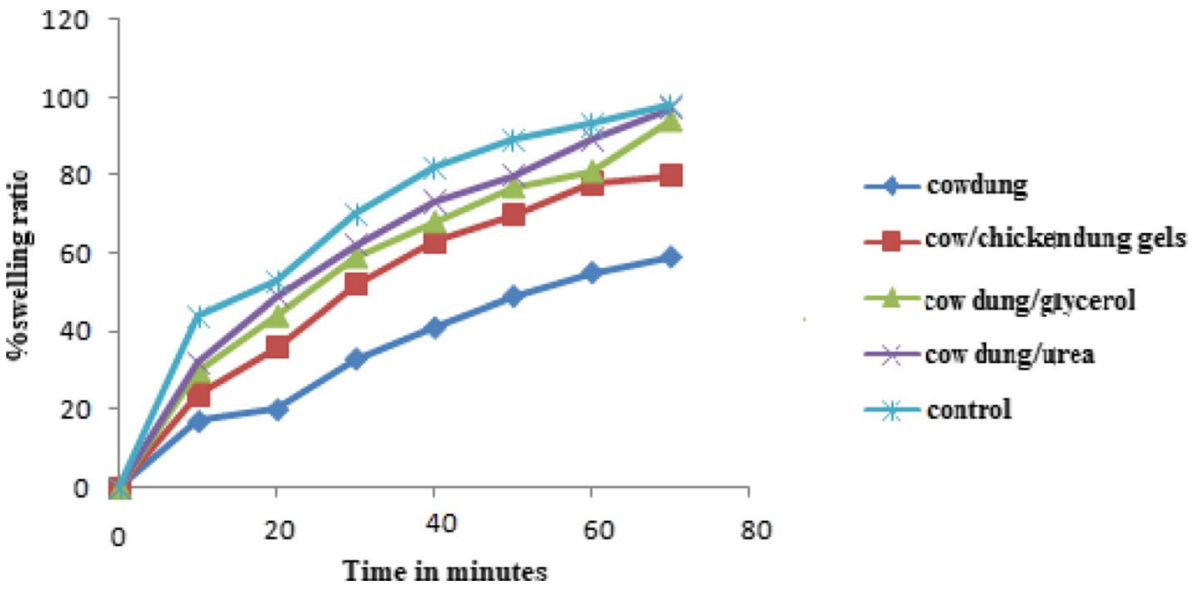

The effect of immersing of time on swelling kinetics of unmodified manure and its modified forms in water is presented in Fig. 9. The modified forms had a swelling ratio of 300 times of its dried weight for all the gels after $10 \mathrm{~min}$. With the increase of immersing of time up to $1 \mathrm{~h}$, the swelling ratio of hydrogels gradually increased up to $500.0 \mathrm{~g} \mathrm{~g}^{-1}$. Further increasing of immersing of time up to $3 \mathrm{~h}$, the water absorption of hydrogels is relatively increased to swelling ratio $800.0 \mathrm{~g} \mathrm{~g}^{-1}$. It is noticeable from the figure that treatment of cow dung with a various cross-linkers affects the swelling behavior. The swelling behavior can be useful in aerating the soil when the modified manure gel is applied in farms as a source of water.

It was observed that urea and glycerol-treated cow dung has a high swelling rate as compared to chicken dung crosslinked material. The difference could be due to the proportion of the resulted cross linking that forms a complex network in the matrix system during gelatinization, restricting rehydration of cow-dung matrices. This observation agrees with the finding of other researches' which stated relation between various cross-linker and swelling ratio of particles (Zheng et al. 2011; Zhou et al. 2011). A similar observation was also reported by Pereira et al. (2017) relating the swelling ability of hydrogels with its ionic properties. From the study, the use of polar cross-linker contributed to the increased degree of swelling. The material was then applied for use in the growth of some selected plants.

\section{Moisture retention}

The data from Karl Fischer moisture analysis as the experiment progressed for both the potato and the spinach were plotted and are presented in Fig. 9.

The results in Fig. 10 show a decrease of moisture content with time. It was observed that there was a high rate of moisture loss in spinach which had broader leaves as compared to potato while using all the modified forms of manure. From the control, information about the requisite
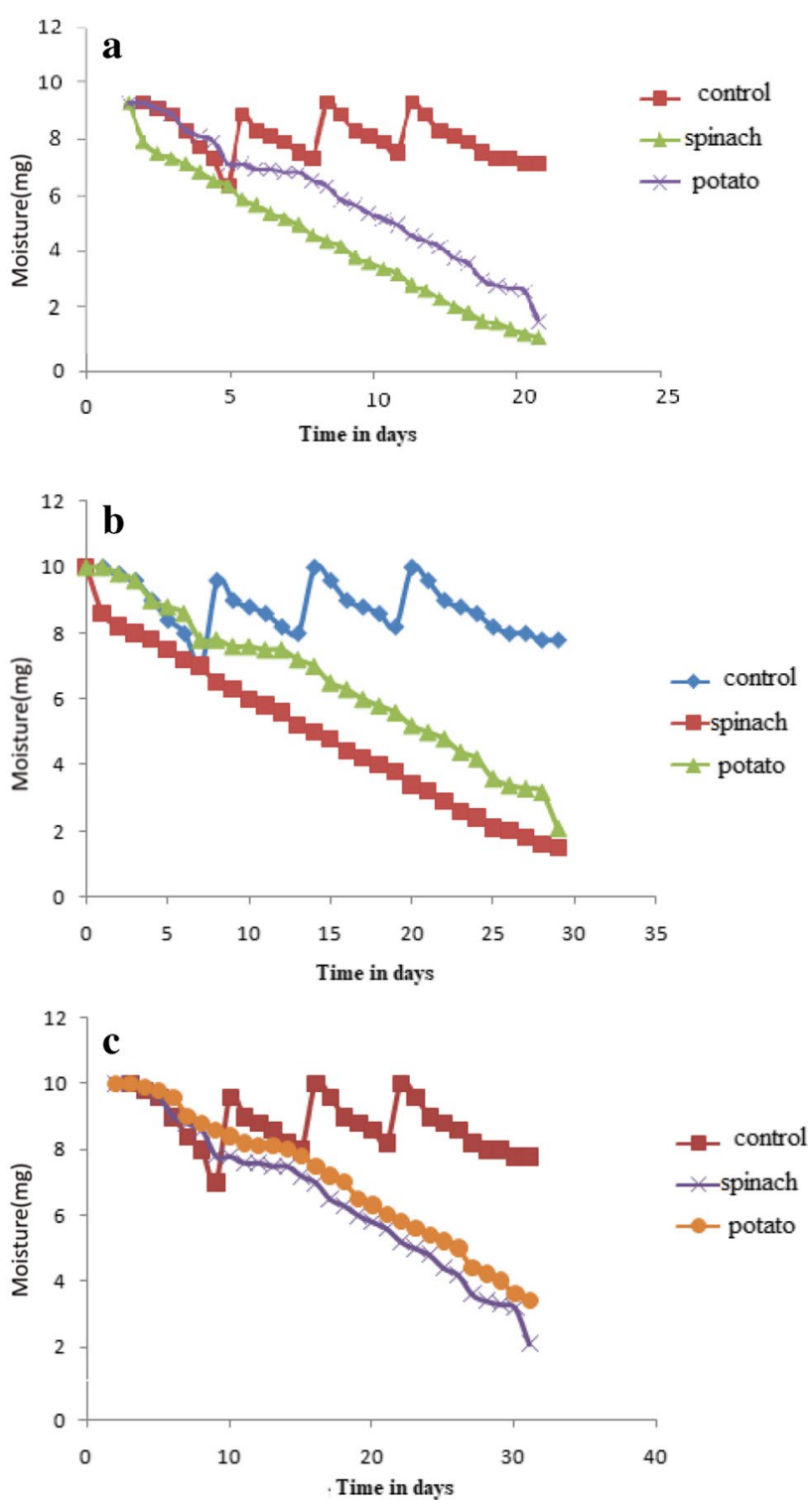

Fig. 9 Moisture retention capacity for plants in a manure-chicken dung, b manure-glycerol, and $\mathbf{c}$ manure-urea gels against time 
Fig. 10 Moisture retention capacity for plants in the unmodified and modified manure

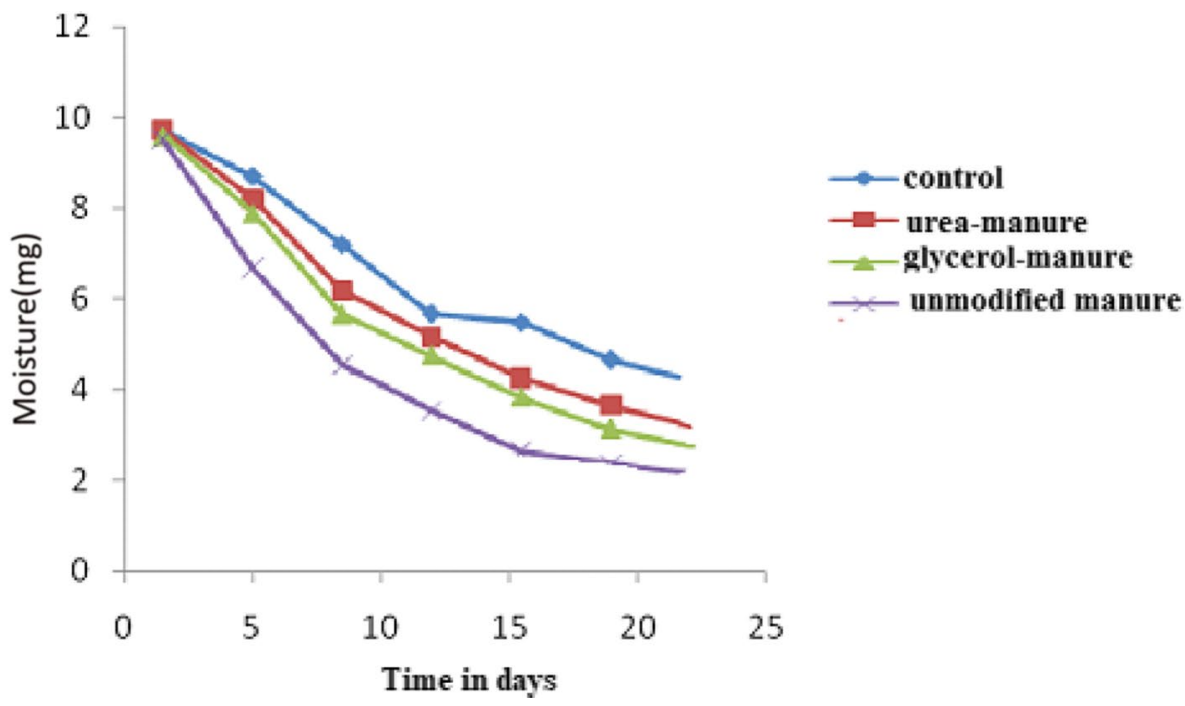

moisture content for the plants' need was established. It was found that the control needed $50.0 \mathrm{ml}$ of water per week to sustain proper healthy growth. An analysis to compare the variation of moisture loss was done while growing spinach plant using the parent and modified materials. The results obtained are presented in Fig. 10.

The figure shows the variation of moisture content with time for the different modified forms of cow-dung manure. It was observed that the unmodified manure had the poorest moisture retention capacity as compared to the other three gels. This observation agrees with the finding of Zhou et al. (2011) which stated the relation between various cross-linker and swelling ratio of particles. Among the modified forms, the urea-modified material showed a better water retention capacity. This can be attributed to the higher number of hydrogen bonds in the gel as compared to the other modified forms (Karve and Kale 1992).

\section{Determination of growth rate for modified and unmodified manure}

All the experiments on the growth plants were carried out in a controlled environment to simulate a hot and arid area with temperatures ranging between 30 and $45^{\circ} \mathrm{C}$. The results obtained from the experimental data showing the investigated leaf growth characteristics provided the relationship between growth rates, as a function of time is presented graphically, as shown in Fig. 11.

The results obtained show a growth rate with similar profile for modified and unmodified manure, but at different rate constants. The growth rate has a similar profile to that of the swelling rate which has a direct relationship with the water holding capacity of the manure derivative. It was observed that the higher growth capacity of the plant, the higher the water holding capacity of the derivative in is growing in. The cow dung-urea derivative was found to have had the
Fig. $11 \%$ relative growth rate against time

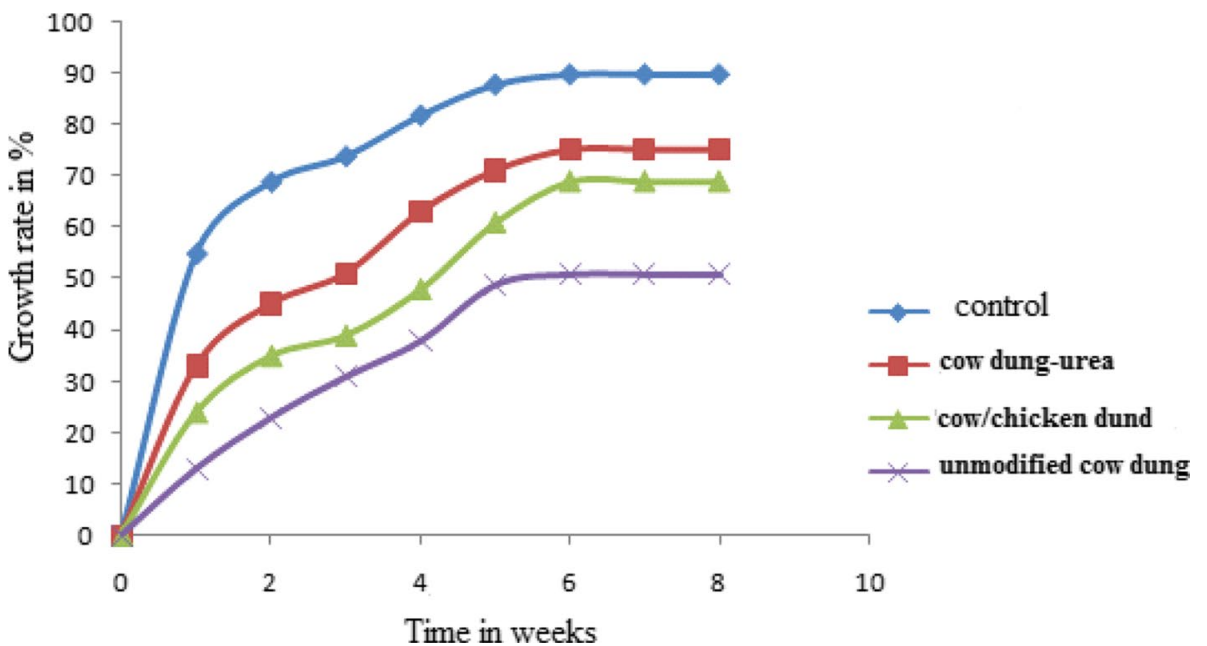


highest swelling rate due to the high degree of cross linking and thus provided the highest growth rate (Metters 2006; Suzuki et al. 2008). The unmodified cow dung had the poorest moisture retention and hence gave the poorest growth rate. This indicates that cross linking has a positive effect of growth promotion of plants due to water retention ability.

\section{Application}

\section{Observed plant health as a measure of moisture retention}

The plants used in this experiment are presented in the photographs, as presented in Fig. 12. In the experiment, the health of the plants was observed throughout the entire experimental period.

During the experiment, the control was watered daily to maintain constant moisture needed by the plants as the experiment proceeded; otherwise, the plant wilted due to plasmolysis. In the same environment, it was found that the chicken dungmodified manure gel sustained duration of 6 weeks before the plants showed signs of wilting. Similar results were observed when the growth media was hydrated with urea and glycerolmodified material. Results for the growth rates due to the other two modified manure gels under study were tested on linear regression and the results are recorded, as shown in Table 1.

It was observed that the cow dung-urea hydrogel had the highest growth rate for both the spinach and the potato plants. This can be attributed to the high moisture content shown by the gel during the optimization studies, which then solubilized the nutrients from the substrate availing them for plant uptake. In addition, the chicken dung-modified gels performed better than the unmodified manure. This shows
Table 1 Summary data for linear regression and growth rate for modified and unmodified manure

\begin{tabular}{lllll}
\hline Sample & Experiment & $R^{2}$ & $\begin{array}{l}\text { Relative } \\
\text { growth rate } \\
\text { week }^{-1}\end{array}$ & $\begin{array}{l}\text { Mean } \\
\text { leaf/tuber } \\
\text { weight } \mathrm{g}^{-1}\end{array}$ \\
\hline Manure-urea & Spinach & 99.7 & 0.0355 & 50.1 \\
& Potato & 99.4 & 0.0461 & 360.3 \\
Manure-glycerol & Spinach & 98.9 & 0.0321 & 49.3 \\
& Potato & 98.5 & 0.0432 & 290.1 \\
Manure-chicken & Spinach & 98.1 & 0.0301 & 48.7 \\
dung & Potato & 98.2 & 0.0428 & 287.5 \\
Unmodified & Spinach & 94.2 & 0.0298 & 44.2 \\
manure & Potato & 93.8 & 0.0289 & 280.1 \\
Control & Spinach & 99.9 & 0.0379 & 60.2 \\
& Potato & 99.9 & 0.0380 & 375.0 \\
\hline
\end{tabular}

that there would be improvement upon the use of the modified gels by farmers to improve their yields.

\section{Conclusions}

The study successfully modified the manure by cross linking with urea, glycerol and chicken dung. The cross linking was confirmed by Fourier transform infra-red spectroscopy (FTIR). The modified manure materials showed a high swelling capacity capable of aerating the soil in the fields that they are applied for a suitable aeration of roots. It also showed a water conservation capacity of $90 \%$ as compared to its raw for whose capacity was $10 \%$. This was due to the presence of cavities capable of holding water. The results

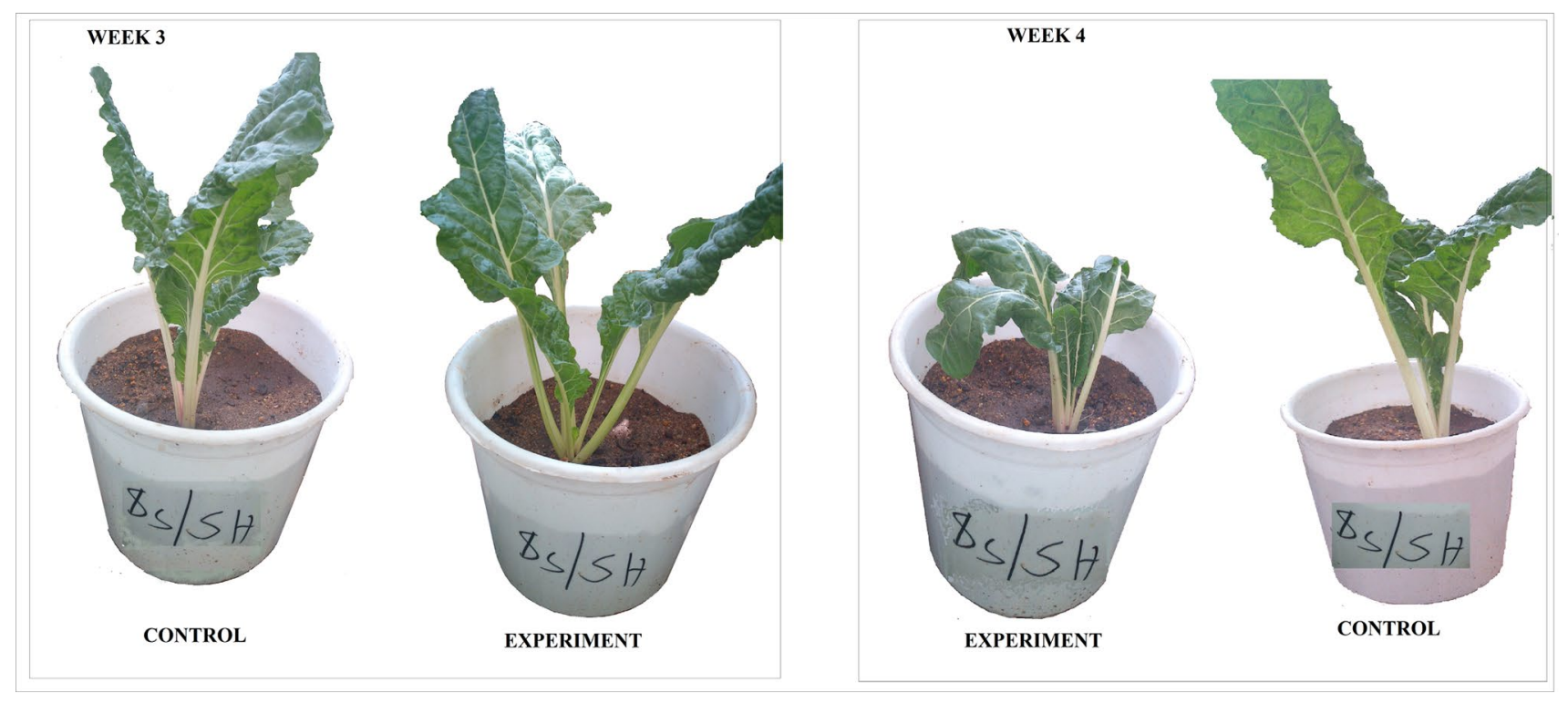

Fig. 12 Plants at weeks 3 and 4 for manure-chicken dung gel and its control 
established that the material had superabsorbent property with higher swelling capacities $\left(300 \mathrm{~g} \mathrm{~g}^{-1}\right)$ within the first of 5 min of contact. Thus, there was a relationship between cross linking and swelling of the manure. The UV-Vis analysis showed no evidence of starch iodine complex in the modified material. The application cow-chicken dung gels reached critical moisture at week 6 before the plants wilted, showing a sustainable use of those readily available resources to improve the quality of life. The thermostability of that material was confirmed by TGA, where the onset starting points for the first degradation steps for cow dung-urea, cow-chicken dung gel, cow dung-glycerol, and the cow-dung-unmodified material were $245,220,228$, and $198{ }^{\circ} \mathrm{C}$, respectively. This implies that the material can withstand higher temperatures than those experienced in the arid areas. This indicates that all the modified manure gels in this study which can be easily produced have a potential application in farming due to its higher water retention of the resulting gels thus remediation or improving degraded soils.

Open Access This article is distributed under the terms of the Creative Commons Attribution 4.0 International License (http://creativeco mmons.org/licenses/by/4.0/), which permits unrestricted use, distribution, and reproduction in any medium, provided you give appropriate credit to the original author(s) and the source, provide a link to the Creative Commons license, and indicate if changes were made.

\section{References}

Chowdary KPR, Chandra DU (2009) Preparation and evaluation of cross linked starch urea-a new polymer for controlled release of diclofenac. Int J Chem Sci 7(4):2239-2245

González-Pérez M, Vidal TP, Colnago LA, Martin-Neto L, Otero XL, Debora MBP, Gomes FH (2008) ${ }^{13} \mathrm{C}$ NMR and FTIR spectroscopy characterization of humic acids in spodosols under tropical rain forest in southeastern Brazil. Geoderma 146:425-433. https://doi. org/10.1016/j.geoderma.2008.06.018

Kampouris EM, Andreopoulos AG (1989) Gel content determination in cross-linked polyethylene. Boimater 10(3):206-208. https://doi. org/10.1016/0142-9612(89)90026-4

Kaneko Y, Yoshida R, Sakai K, Sakurai Y, Okano T (1995) Temperatureresponsive shrinking kinetics of poly ( $N$-isopropylacrylamide) copolymer gels with hydrophilic and hydrophobic comonomers. J Membr Sci 101:13-22. https://doi.org/10.1016/0376-7388(94)00268-4169

Karve MS, Kale NR (1992) A spectrophotometric method for the determination of iodine binding capacity for starch and its components. Starch-Starke 44(1):19-21. https://doi.org/10.1002/star.19920440106

Kaye D (1968) Antibacterial activity of human urine. J Clin Invest 47:2374-2390. https://doi.org/10.1172/JCI105921

Mainka DIH, Laue M, Herrmann DIAS (2015) Lignin Powder as a filler for thermoplastic lightweight design components. Atz Worldwide 117(3):32-35. https://doi.org/10.1007/s38311-015-0171-1

Metters AT (2006) Hydrogels in controlled release formulations: network design and mathematical modeling. Adv Drug Delivery Rev 58:1379-1408. https://doi.org/10.1016/j.addr.2006.09.004165

Mwangi IW, Ngila JC, Ndungu P, Msagati TAM, Kamau JN (2013) Mobilized Fe(III)-doped titanium dioxide for photodegradation of dissolved organic compounds in water. J Environ Sci J Environ Sci Pol Res 20(9):6028-6038. https://doi.org/10.1007/s1135 6-013-1600-6
Nagahara S, Matsuda T (1996) Hydrogel formation via hybridization of oligonucleotides derivatized in water-soluble vinyl polymers. Polym Gels Netw 4:111-127. https://doi.org/10.1016/0966-7822(96)00001 $-9161$

Peppas NA, Hilt JZ, Khademhossein A, Langer R (2006) Hydrogels in biology and medicine: from molecular principles to bionanotechnology. Adv Mater 18(13):45-1360. https://doi.org/10.1002/ adma.200501612166

Pereira AGB, Martins AF, Paulino AT, Fajardo AR, Guilherme MR, Faria MGI, Linde GA, Rubira AF, Muniz EC (2017) Recent advances in designing hydrogels from Chitin and Chitin-Derivatives and their impact on environment and agriculture. Rev Virtual Quim 9(1):370386. https://doi.org/10.21577/1984-6835.20170021

Shibayama M (2012) Structure-mechanical property relationship of tough hydrogels. Soft Matter 8:8030-8038. https://doi.org/10.1021/ma971 $411 b$

Suzuki D, Sakai T, Yoshida R (2008) Self-flocculating/self-dispersing oscillation of microgels. Angew Chem Inst Educ 47:917-920. https ://doi.org/10.1002/anie.200703953162

Voorend W, Lootens P, Nelissen H, Roldán-Ruiz I, Inzé D, Muylle H (2014) LEAF-E: a tool to analyze grass leaf growth using function fitting. Plant Methods 10(37):1-13. https://doi. org/10.1186/1746-4811-10-37

Wang L, Zhang C, Wu F, Deng N (2007) Photodegradation of aniline in aqueous suspensions of microalgae. J Photochem Photobiol B Biol 87:49-57. https://doi.org/10.1016/j.jphotobiol.2006.12.006

Wang Q, Xie X, Zhang X, Zhang J, Wang A (2010) Preparation and swelling properties of $\mathrm{pH}$-sensitive composite hydrogel beads based on chitosan-g-poly (acrylic acid)/vermiculite and sodium alginate for diclofenac controlled release. Int J Biol Macromol 46:356-362. https://doi.org/10.1016/j.ijbiomac.2010.01.009

Wawro D, Kazimierczak J (2008) Forming conditions and mechanical properties of potato starch films. Fibres Text East Eur 16(71):106-112

Yoshida R, Takahashi T, Yamaguchi T, Ichijo H (1996) Self-oscillating gel. J Am Chem Soc 118:5134-5135. https://doi.org/10.1021/ja960 2511163

Zhang JP, Wang Q, Wang AQ (2007a) Synthesis and characterization of chitosan-graft-poly(acrylic acid)/attalpulgite superabsorbent composites. Carbohydr Polym 68:367-374. https://doi.org/10.1016/j. carbpol.2006.11.018

Zhang J, Zhao S, You C, Qi H, Chen C (2007b) Rapid hydration preparation of calcium based sorbent made from lime and fly ash. Ind Eng Chem Res 46:5340-5345. https://doi.org/10.1021/ie990511y

Zhang LF, Rakotondradany AJ, Myles HF, Webste TJ (2009) Arginineglycine-aspartic acid modified rosette nanotube-hydrogel composites for bone tissue engineering. Biomaterials 30:1309-1320. https ://doi.org/10.1016/j.biomaterials.2008.11.020

Zheng Y, Liu Y, Wang A (2011) Fast removal of ammonium ion using a hydrogel optimized with response surface methodology. Chem Eng J 171:1201-1208. https://doi.org/10.1016/j.cej.2011.05.026

Zhou C, Wu Q, Yue Y, Zhang Q (2011) Application of rod-shaped cellulose nanocrystals in polyacrylamide hydrogels. J Colloid Interface Sci 353:116-123. https://doi.org/10.1016/j.jcis.2010.09.035

Zimmermann MB, Andersson M (2012) Assessment of iodine nutrition in populations: past, present, and future. Nutr Rev 70(10):553-570. https://doi.org/10.1111/j.1753-4887.2012.00528.x

Publisher's Note Springer Nature remains neutral with regard to jurisdictional claims in published maps and institutional affiliations. 